\title{
Importance of Personal Dose Equivalent Evaluation in Fukushima in Overcoming Social Panic
}

Kohji Yoshida ${ }^{1}$, Kanami Hashiguchi ${ }^{1}$, Yasuyuki Taira ${ }^{1}$,Naoki Matsuda ${ }^{2}$, Shunichi

Yamashita $^{3,4}$ and Noboru Takamura ${ }^{1}$

${ }^{1}$ Department of Global Health, Medicine and Welfare and ${ }^{3}$ Department of Radiation

Medical Sciences, Nagasaki University Graduate School of Biomedical Sciences

${ }^{2}$ Center for Frontier Life Sciences, Nagasaki University

${ }^{4}$ Fukushima Medical University

Corresponding to

Noboru Takamura, M.D., Ph.D.

Professor and Chairman

Department of Global Health, Medicine and Welfare

Nagasaki University Graduate School of Biomedical Sciences

TEL: +81-95-819-7170

FAX: +81-95-819-7172

E-mail: takamura@nagasaki-u.ac.jp 


\begin{abstract}
We evaluated the relationship between the reported ambient dose equivalent $\left(H^{*}(10)\right)$ and the individual dose rate recorded by medical staff in Fukushima City after the accident at the Fukushima Daiichi nuclear power plant, following a 9.0-magnitude earthquake struck the east coast of Japan. Personal dose equivalent $\left(H_{\mathrm{p}}(10)\right)$ ranged from 0.08 to $1.63 \mu \mathrm{Sv} / \mathrm{h}$ and $H^{*}(10)$ ranged from 0.86 to $12.34 \mu \mathrm{Sv} / \mathrm{h} . H_{\mathrm{p}}(10)$ from March to July 2011 were significantly lower than $H^{*}(10)$. The relationship between these dose equivalents were moderately correlated. The regression equation was calculated as follows:

$H_{\mathrm{p}}(10)=0.0696 * H^{*}(10)+0.0538$. Our preliminary data show that, in Fukushima, the individual dose is much lower than that determined $H^{*}(10)$. It is important to evaluate $H_{\mathrm{p}}(10)$ in order to lessen the anxiety of the general population in Fukushima.
\end{abstract}




\section{INTRODIUCTION}

On March 11, 2011, a 9.0-magnitude earthquake struck the east coast of Japan. This natural disaster also caused substantial damage to the Fukushima Daiichi nuclear power plant $^{(1)}$. During the initial phase of the accident, iodine-131, cesium-134 and cesium-137 were released from the reactor, reaching as far as Fukushima City, $63.0 \mathrm{~km}$ away from the plant. Ambient dose equivalent $\left(H^{*}(10)\right)$ data has been collected and reported by Fukushima Prefecture since March 13. Dose rate has been elevated since the afternoon of March 15; the highest dose rate (24.18 $\mu \mathrm{Sv} / \mathrm{h})$ was recorded at 18:30 on this day. The background dose in Fukushima City before the crisis was $0.04 \mu \mathrm{Sv} / \mathrm{h}$.

Since March 15, radiological specialists from Nagasaki University have served on the medical relief team organized at Fukushima Medical University Hospital (Fukushima City). These specialists were prepared for the treatment of acute radiation syndrome, within a framework of WHO's Radiation Emergency Medical Preparedness and Assistance Network (REMPAN) ${ }^{(2)}$, and monitored individual doses using personal dosimeters during their stay in Fukushima City. In this communication, we evaluate the relationship between the reported $H^{*}(10)$ and the personal dose equivalent $\left(H_{\mathrm{p}}(10)\right)$ recorded by medical staff in Fukushima City ${ }^{(3,4)}$. 


\section{Methods}

Radiological specialists from Nagasaki University were dispatched to Fukushima Medical University from March to July 2011. During this period, three nurses were dispatched in turns, and each recorded $H_{\mathrm{p}}(10)$ using personal dosimeters (MYDOSE mini ${ }^{\circledR}$, Hitachi-Aloka Medical, Tokyo, Japan). Nurses worked primarily inside the university hospital building to prepare for the treatment of acute radiation syndrome and for the education of general nurses in the hospital, but they worked outside (1-6 hours / day), in order to identify the contamination areas around the hospital. Recorded daily doses were divided by 24 to calculate the dose rate $(\mu \mathrm{Sv} / \mathrm{h})$ and were compared with daily $H^{*}(10)$ in Fukushima City reported by Fukushima Prefecture. 


\section{Results and Discussion}

$H_{\mathrm{p}}(10)$ ranged from 0.08 to $1.63 \mu \mathrm{Sv} / \mathrm{h}$ and $H^{*}(10)$ ranged from 0.86 to $12.34 \mu \mathrm{Sv} / \mathrm{h}$. $H_{\mathrm{p}}(10)$ were significantly lower than $H^{*}(10)(P<0.001$, Mann-Whitney's U-test). The relationship between these dose rates is shown in Figure 1. These dose rates were moderately correlated ( $\mathrm{r}=0.68, P<0.001$, Spearman's rank correlation test). The regression equation was calculated as follows:

$H_{\mathrm{p}}(10)=0.0696^{*} H^{*}(10)+0.0538$

Our preliminary data show that, in Fukushima, the $H_{\mathrm{p}}(10)$ is much lower than that determined $H^{*}(10)$. According to the regression equation, if the $H^{*}(10)$ is $10 \mu \mathrm{Sv} / \mathrm{h}$, the $H_{\mathrm{p}}(10)$ is estimated to be $0.75 \mu \mathrm{Sv} / \mathrm{h}$, and even if the $H^{*}(10)$ is $24.18 \mu \mathrm{Sv} / \mathrm{h}$ (the highest dose rate recorded in Fukushima City), the $H_{\mathrm{p}}(10)$ is estimated to be $1.74 \mu \mathrm{Sv} / \mathrm{h}$. It is estimated that this gap is mainly caused by shielding effects. During the measurements, nurses were mainly working at the first floor inside the building. According to the technological report issued by International Atomic Energy Agency (IAEA) ${ }^{(5)}$, shielding factor for surface deposition, such as ground contamination, is 0.05 for first and second floor of three or four story structures (500 to $1,000 \mathrm{~m}^{2}$ per floor), when shielding factor for $1 \mathrm{~m}$ above an infinite smooth surface is $1.0^{(6)}$. When we estimate external radiation exposure doses in Fukushima, shielding effects should be carefully considered.

After the accident, according to the recommendation of the International Committee on Radiation Protection, the Japanese government outlined guidelines for evacuation and for the usage of playgrounds based on the sum of $H^{*}(10)$, and designated areas where cumulative $H^{*}(10)$ reached more than $20 \mathrm{mSv}$, such as Iitate Village, as 
“deliberate evacuation areas”. This announcement caused social panic, even outside Fukushima Prefecture ${ }^{(7)}$. Many people purchased dosimeters in the effort to identify "hot spots". However, as shown in this report, we should remember that $H^{*}(10)$ measured by dosimeters may overestimate $H_{\mathrm{p}}(10)$.

Local authorities in Fukushima Prefecture have already started to distribute glass badges to children for the evaluation of their $H_{\mathrm{p}}(10)$. We need to emphasize the importance of $H_{\mathrm{p}}(10)$ evaluation in order to lessen the anxiety of the general population in Fukushima Prefecture. 


\section{References}

1. Christodouleas JP, Forrest RD, Ainsley CG, Tochner Z, Hahn SM, Glatstein E. Short-term and long-term health risks of nuclear-power-plant accidents. N Engl J Med 364, 2334-41 (2011).

2. World Health Organization. Radiation accidents and emergencies. http://www.who.int/ionizing_radiation/a_e/en/

3. Editorial. Personal dose equivalent, $H p(d)$, and reference point for calibration. Rad Prot Dosimet 121, 209-10 (2006).

4. Hupe O, Ankerhold U. Determination of ambient and personal dose equivalent for personnel and cargo security screening. Rad Prot Dosimet 121, 429-37 (2006).

5. Generic procedures for assessment and response during a radiological emergency. IAEA-TECDOC-1162. IAEA, Vienna

6. Jacob P, Meckbach R. Shielding factors and external dose evaluation. Rad Prot Dosimet 21, 79-85 (1987).

7. Normile D. Japan disaster. Citizens find radiation far from Fukushima. Science 332, 1368 (2011). 


\section{Figure Legends}

Figure 1: Map of Fukushima Prefecture.

Figure 2: Relationship between ambient dose rates and individual dose rates in Fukushima City. 


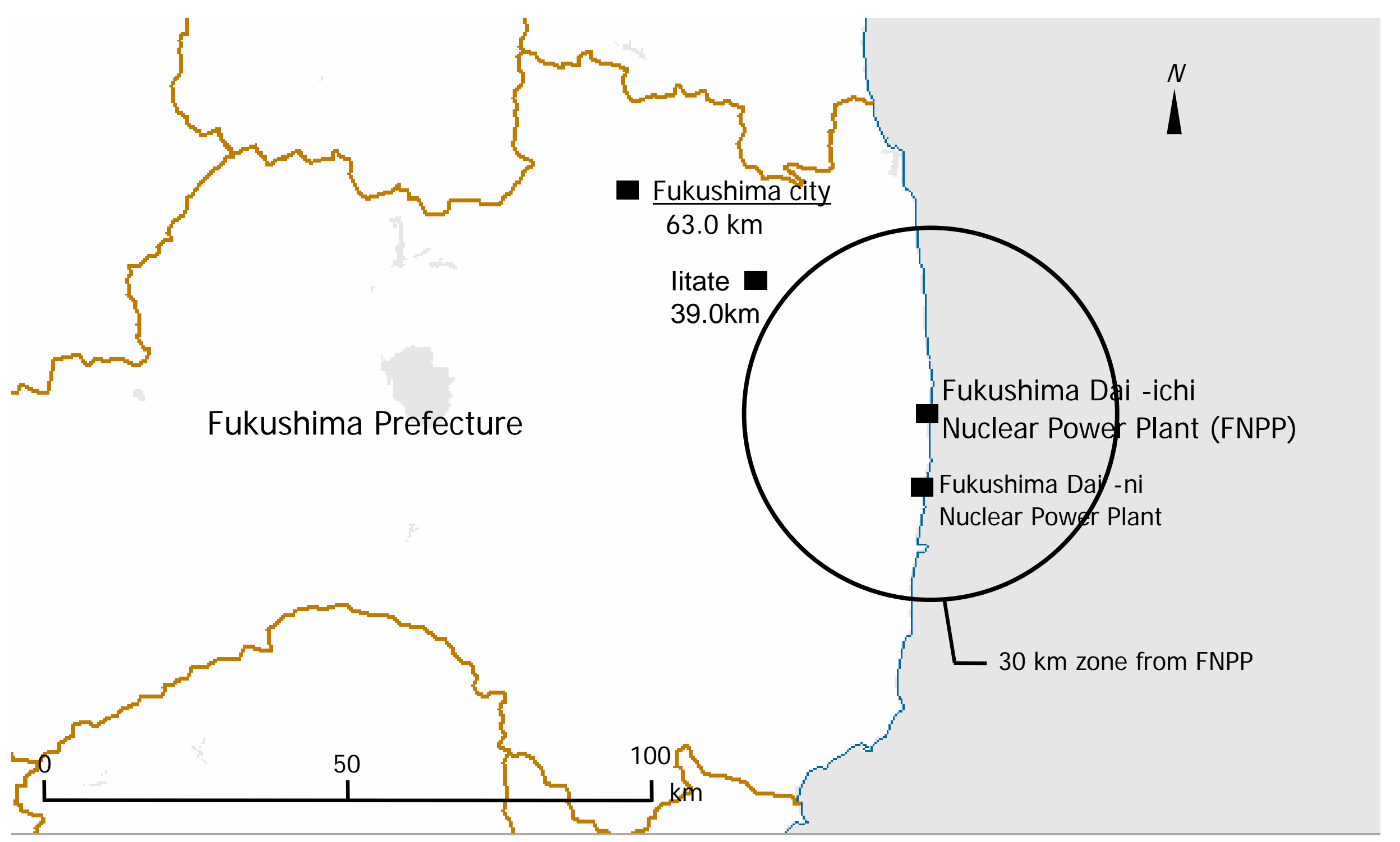


Figure 2

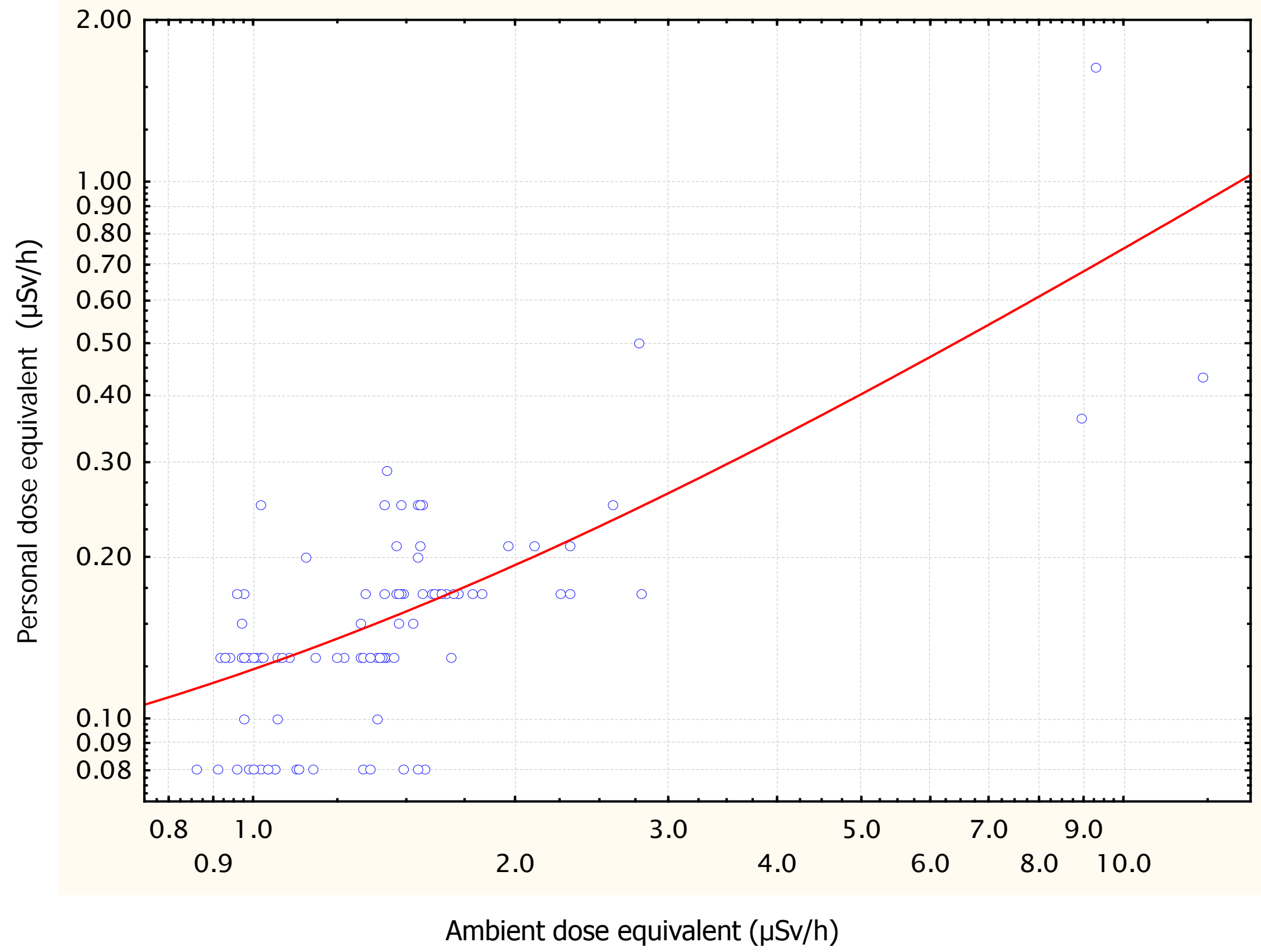

